\title{
15
}

\section{Cooperation in small forest producers in Bolivia}

\author{
Jorge Téllez Carrasco and José Blanes Jiménez
}

\section{Context}

In the Chiquitania region of Bolivia, precious woods are products of high value that can be acquired from communities through local intermediaries at very low prices. Timber buyers acquire timber from people and communities through a system of loans and exchanges that often disadvantage small producers. Generally, timber leaves the area unprocessed. Small producers in the region requested support, through their municipal governments, from the Spanish Cooperation Agency to break into the added value of wood products. In 2003, the governments of Bolivia and Spain agreed to undertake a forestry development project in the Chiquitania region. Given that similar initiatives had not delivered the expected results, a pilot project and preliminary documentation was undertaken. Methodological advice and support came from the University of Cordoba in Spain and Centro Boliviano de Estudios Multidisciplinarios (CEBEM) in Bolivia. Later, with guidance from CEBEM and the Bolivian component of the International Social Analysis Systems (SAS2), Carleton University (Ottawa) and the International Development Research Centre of Canada (IDRC) got involved.

Despite the decentralization of forest management that started in Bolivia in the 1990s, forest participants failed to properly consolidate their attributions, while many of the communities and other social groups who had been excluded in previous forest regimes gained access to forest transition and profitable logging. Among the reasons for this were the heavy reliance on international funding, lack of technical capacity, limited access to information, poor road infrastructure and difficulties in accessing credit. As a result, intermediaries, rather than small producers themselves, were the principal beneficiaries of international support. Therefore, the question arose as to how to ensure that international cooperation/support was helpful in generating higher and more sustainable incomes for families from the most disadvantaged social groups.

From the research standpoint, the project was conceived as a base community forest management assessment in the Chiquitania which would inform the next design phase. With this in mind, the project considered four main issues:

- whether or not the forest community had productive potential (e.g., ecological, silvicultural and forest management); 
- whether the Forestry Law could be a framework for sustainable community management;

- whether the application of the Forestry Law was consistent with its original spirit; and

- did the logic and behaviour of local participants encourage community forestry development, and, if so, was there a market for forest products?

\section{Organization/structure}

The Chiquitania Forestry development project was undertaken within the VII Joint Hispano-Bolivian Cooperation Commission (2003). In Bolivia, the Forestry Law gives municipalities responsibility for promoting local forestry development activities. Since the appropriation process takes place at this level so that they can be sustainable, it was agreed that field activities be conducted through their forestry units, involving various municipalities. Institutional coordination was undertaken by the Natural Resources Directorate of the Prefecture of the Department of Santa Cruz. At a national level, activities were coordinated by the Vice-Ministry of Biodiversity, Forest Resources and Environment. The project established a management unit in the area to manage the project and coordinate technical assistance. Thus, collaborative research coordination for social action was established in this unit.

The project involved a wide range of participants. To facilitate the adoption of a research-action approach, project coordination was undertaken by a CEBEM researcher. This facilitated the establishment of strategies for monitoring social interaction, support and methodological design. It also ensured that new project participants received training. Processes of collaborative research-action were directed not only at researchers and consultants, but also at municipal technicians, mayors and community leaders.

The project also drew on the everyday knowledge of the local project participants. Further, key players helped to advance the project. External assistance was sought for knowledge regarding forestry, business, law and development cooperation.

The main source of funding was from Spanish Cooperation. It helped cover technical assistance in the formulation and development stage of the project. The Prefecture of Santa Cruz and the municipalities of Velasco Province also made contributions to the project. Finally, CEBEM, Cordoba University and Carleton University financed part of the systematization stage.

\section{Activities}

The development of experimental logic was based on three distinct stages: description of the formulation process; establishment of the social basis for the facilitation of processes; and their successive implementation. Participation in these stages was made through consultancies.

During the first phase, occurring in mid-2004, actions were formulated that served as a basis for the research approach and funding. Beyond agreeing to a 
collaboratively formulated development action, progress in improving living standards of the target population was barely perceptible. At the end of 2004, the project received further technical assistance. On this occasion, research work was combined with the coordinating role of the project. While some intermediate results were achieved during this phase, these results have not provided sufficient certainty about how to get participants and their communities to respond, compared with the processes considered most critical for the success of the project.

This situation changed in early 2006 when the project began to operate as a business and activities became less experimental, causing take-off of the processes. In the third phase of the project, there is a turning point coinciding with the achievement of the first one, generating striking results regarding the interests of beneficiaries. This gave the project the necessary impetus to carry out its social strategy.

At this point, monitoring of the project was left aside to start systematizing a model that was already paying off and that allowed for testing the validity of a doctoral thesis. This systematic work was interrupted only by a final consultation by the middle of that year, which accompanied the elaboration of municipal forest development plans. This occasion allowed updating the achievements for the last time.

\section{Outcomes}

The initial outcome was a list of recommendations from the evaluation of community forest management practices in the Chiquitania. This result has evolved into a methodological accompaniment to the process of building and strengthening a group of wood producers and processors in Velasco province. This group has managed timber processing and marketing of timber products on better terms than previous ones. At present there are drying and milling centres in three Velasco municipalities, managed as commercial enterprises involving project beneficiaries.

The case study validates the fact that dialogue between knowledge systems and the interests involved in community forestry process allows the outcome path to become gradually more advanced and impressive. This project has been able to introduce a working methodology for the field of international cooperation that can address forest development in complex social contexts with greater potential for success. In turn, these new methodological developments have helped to overcome the lack of corporate knowledge that exists around community forestry.

In addition, this project has provided insight into how the international understanding of forestry development is very weak regarding its recognition of social complexities and interactions in and between the communities involved. This is important because it has been proved that some of the decisions that affect small-scale wood production in the Velasco province do not concern communities living in the forest, but rather other factors such as consumers, intermediate channels or international solidarity. 
Municipal forestry policies in the Velasco province had major shortcomings. Despite the importance of the exploitation of forests to these municipalities, and the potential for economic development, attention is focused on other sectors such as health or livestock. This implied a lower allocation of funds to this sector. Effective support to municipal forestry units, and strengthening of producer organization plans for the forestry sector were formalized, complementing public development policies and thereby improving the final appropriation by the participants in the forestry regime. This step facilitated the adoption of much more comprehensive and developed actions by the sector, allowing for the generation of models for permanent forest production areas of the country.

This project has benefited many with fragile household economies, allowing them to significantly improve their incomes sustainably. With the success of such initiatives, important opportunities will open up to address poverty in other rural areas.

The generated model has opened up significant opportunities for business collaboration between Bolivia and other wood-consuming countries. Small farmers who have participated in the initiative can now interact on an equal footing with companies that dominate distribution channels. In return, companies in the consumer countries enjoy a product that is more consistent and conforms to the requirements of a market increasingly focused on relationships with the consumer. Additionally, links were established between universities in Bolivia and Spain to develop joint research and development. All of this has contributed to real cooperation between states, improving the competitiveness of countries consuming tropical timber, and contributing to improved living conditions in those forests.

In addition, promoting a sustainable timber harvesting has contributed to better preservation of forest ecosystems in Chiquitania, since profitability enables it to face the advance of the agricultural frontier from the city of Santa Cruz and neighbouring Brazil. 